\title{
Saudi Female International College Students' Self- Identities Through the Use of Social Media in the United States
}

\author{
Tahani Alruwaili \\ Heng-Yu Ku \\ University of Northern Colorado, USA
}

\begin{abstract}
This study explored 14 Saudi female international college students' self-identities through social media use while they were studying in the United States. Data was collected by semistructured interviews. In addition, participants were asked to draw pictures that represented how they experience social media use in Saudi Arabia and in the United States as part of the interviews. The findings revealed that many participants indicated they experienced some changes to their identities after coming to the United States. Many of the participants expressed they were more open and more independent after coming to the United States. They felt they could express their identities on social media to a greater degree and enjoyed using it to connect with others. Although most of the participants became more comfortable with interaction and expression on social media in the United States, many of them still retained some measures to ensure their privacy.
\end{abstract}

Keywords: privacy, Saudi women, self-identities, social media

\section{INTRODUCTION}

The phrase "social media" is a broad term used to denote any technological system used for collaboration, interaction, and/or community (Tess, 2013). This term covers various types of interactive technologies such as networking sites, collaborative wikis, blogs, content communities, multimedia platforms, online game worlds, and online social worlds (Kaplan \& Haenlein, 2010; Tess, 2013). These overarching 
categories serve as general types of social media, whereas sites such as Facebook or Twitter represent specific examples (Tess, 2013).

Increased exposure to social media is changing the process of developing selfidentity. According to Giddens (1991), self-identity is defined as "the self as reflexively understood by the person" (p. 53). This definition contends that selfidentity is created through a fluctuation of personal perceptions of oneself. The establishment and alteration of self-identity in today's globalized world has changed vastly in just a few decades. In fact, with the development of technology like computers, the Internet, and the many varieties of available social media, we have ever-increasing access to different cultures and different societies throughout the world. Papacharissi (2010) explained online interactions often exist on a continuum from personal to professional. This causes a user to negotiate their identity online. As a result, social media is influencing how people maintain and revise their self-identity as they encounter different belief systems, values, and ways of thinking and feeling (J. Y. Kim, 2018).

This research utilized a qualitative theoretical approach and methodology. An exploratory qualitative approach guided the exploration of lived experiences of female international college students from Saudi Arabia and the meaning they attached to forging or altering their identity when using social media. This research was also conducted through the lens of "self-identity theory." Self-identity theory contends that identity is shaped in a constructive manner through individuals' perceptions of themselves and the influence of others around them (Giddens, 1991).

Saudi female college students are a prime example of how self-identity can be shaped and formed in the ways described by self-identity theory. Saudi women undergo culture shock coming to the United States. When they are home, they are extremely limited in their ability to move (InterNations, 2018). They are unable to leave home without the permission of a male responsible for them. If alone, they must be accompanied by a male guardian. Social roles are strictly defined as well, even to their dress code and social conduct. All of these factors serve as powerful influences on the formation of female Saudi identity. When these female students move to the United States to continue their university studies, the immense differences in culture have a strong and enduring impact on their self-identity.

\section{LITERATURE REVIEW}

The development of self-identity has historically been understood as a process of interaction between the culture surrounding an individual and the needs and choices of the particular individual (Pattaro, 2015). One's identity can contain a multitude of meanings dispersed within both the personal and social environments (Giddens, 1991). Self-identity theory contends that the development of one's identity is largely a process of socialization, as it is influenced by personal relationships and one's role in cultural and societal contexts (Earley, 1993). Buckingham (2008) and Papacharissi (2013) noted the importance of social media and the amount of time young people spend on social media as indicators of identity. For example, how they want to be perceived and how they perceived themselves can be observed through their social media. Identity is also increasingly being seen as more fluid, moving from a notion 
of a fixed possession to one of a social process (Buckingham, 2008). Identity is changing and changeable; with the advent of social networking, a concept of an "online identity" has emerged along with questions about similarities and differences between online and offline identities.

For young people, the college experience can be particularly influential in impacting their identity (Ahlquist, 2015). Identity development is not only a private, personal experience, but it also takes place on a public, social scale (Stone, 1981). With the advent of social media technologies, the public element of identity development now has the ability to take place online. This can be especially the case for college students who are typically more familiar with social media and have used it recreationally for years. Dalton and Crosby (2013) reflected on these notions; they explained social media is so ubiquitous for most young people that it has actually become a part of their identities. To advance understanding and theory on identity development, Ahlquist (2015) called for more research on online public identity development regarding young people and college students.

There are several implications for identity formation through social media, particularly for female international students. Past research has shown that as increasing numbers of young women migrated to Western universities, their identities became in flux (Y. Kim, 2011b). This led them to challenge the traditional social roles expected in their home countries. On account of their temporary migration, they are also leaving behind the culture and language of their home country. In Y. Kim's studies (2011a, 2011b), once students spent a significant amount of time in a different culture, their identities became multicultural. They were able to appreciate the practices of other cultural groups while maintaining their own identities. Thus, these female students find themselves forming a new identity (Y. Kim, 2011b) far different from international women of past generations.

Individuals from other countries, cultures, and nationalities are also experiencing changes in the formation of identity due to technology and social media. The Kingdom of Saudi Arabia (KSA) is a developing country in the Middle East and, as such, electronic technologies are just emerging in Saudi culture (Sofi, 2015). In the $\mathrm{KSA}$, an example of the role of culture affecting the formation of identity is the strict separation of males and females in all aspects of life throughout their lifetime (Menea, 2013). Females and males often have their own separate entrances into and areas within homes and public buildings, are educated in segregated schools, and do not participate in entertainment or leisure activities together. Therefore, when these female students move to the United States to continue their university studies, they are not only experiencing both a departure from traditional social roles as well as culture shock, but they are also undergoing changes in the formation of identity due to advanced inclusion of technology and social media within the new culture.

Lefdahl-Davis and Perrone-McGovern (2015) conducted a qualitative investigation of how Saudi female students adjusted to their new lives in the United States. One interesting finding was many Saudi females reported changes in their identity after living in the United States. They reported increased open-mindedness and tolerance for others, and they found social support was a key factor in Saudi females' ability to adjust to living in the United States. Lefdahl-Davis and Perrone- 
McGovern further advocated that research could examine the role of social media in fostering social support for Saudi female international students.

Although research has been conducted on the use of social media and identity for international students studying in Western cultures, little research has been conducted on identity formation via social media for Saudi females studying in the United States (Kutbi, 2015; Xu \& Mocarski, 2014). Further, the research that has been conducted on the relationship between Saudi females and social media has been conducted only in Saudi Arabia (Al-Saggaf, 2011; Aljasir et al., 2014; Guta \& Karolak, 2015). While previous research is useful in understanding how Saudi females negotiate their identity on social media in Saudi culture, it does not explain how this might change when studying in the United States.

When international students come to the United States for their education, they encounter a culture and society that are vastly different from their own. This may influence their identities as they navigate the different cultural settings during their education. Research on interactions between the identities of international students and social media can have implications for international students undertaking education in the United States. In particular, this research may shed more light on how international students from vastly different cultures represent themselves through social media during their education.

The purpose of this study was to explore Saudi female students' self-identities through social media use while they were studying in Saudi Arabia compared with while they were studying in the United States. The study was guided by the following research question: How do Saudi female international college students express their self-identities in social media before and after studying in the United States?

\section{METHOD}

\section{Participants}

The participants of this research were 14 Saudi female students who came from three different universities in the United States. The participants were between the ages of 18 and 40. Five were undergraduate and nine were graduate students. All participants had been living in the United States for at least 2 years. Some of them had been living in the United States for up to 9 years. Their marital status varied. Each participant indicated a frequent use of technology and social media both on their phones and computers. We assigned each participant a pseudonym to protect her identity.

\section{Data Collection}

We employed a semistructured interview format to investigate the perspectives of 14 female college students from Saudi Arabia. We asked a series of interview questions that we wrote before the interview took place but purposefully worded in a flexible manner. The interview questions for this research fell in the categories of demographic questions (age, marital status, degree level, etc.), behavior/experience questions, opinions/values questions, and affective questions (Merriam \& Tisdell, 
2015). In addition, participants also provided artifacts by drawing a picture that represented how they experienced social media in Saudi Arabia and in the United States. They also provided a few sentences explaining their drawings. Sample semistructured interview questions included the following:

- Describe your willingness to share parts of your identity on social media while in Saudi Arabia.

- What kinds of information, pictures, links, etc. on social media related to your identity did you post while in Saudi Arabia?

- Do you think your use of social media while in the U.S. has affected your personal identity? If so, how?

- Thinking about yourself in Saudi Arabia (and then in the U.S.), please draw a picture that represents how you experienced yourself then. Please write a couple sentences that could explain the picture.

\section{Procedures}

We found two Saudi female students through the university one of us attended. We contacted these two students via email and asked if they would like to participate in the study. We provided a consent form that explained the details and assured them of their confidentiality, outlining any possible risks associated with participation in the study. We then used snowball sampling and asked the initial participants if they could help find any other Saudi female college students who would also be a good fit for the study. The initial participants identified other Saudi female students across their universities. We contacted these potential participants by email and explained the purpose of the study in the email.

Once all 14 participants had returned their consent forms, we scheduled face-toface interviews with each participant at an agreed-upon location on their campuses. We conducted the interviews in English. During the interviews, we recorded participant responses electronically, and each interview lasted 60 to 90 minutes. Upon completion of the interview questions, we asked participants to draw and describe pictures of how they saw themselves using social media in two contexts: in Saudi Arabia and in the United States.

\section{Data Analysis}

We transcribed and coded the data using an inductive coding process. In this stage, we used a manual open coding scheme to take notes about any possible themes or phenomena. We followed the data and were open to anything that might emerge in this stage. This careful examination and process of openly assigning codes led to category construction. We grouped these codes together according to likeness and shared overarching themes, then developed subthemes. One of us coded emerging themes and common ideas, which the other then verified.

We also asked the participants to explain the pictures they drew of themselves. We transcribed these conversations and used the transcripts in conjunction with the 
actual drawings to derive similarities and differences between the pictures and the meanings ascribed to them. Finally, we utilized triangulation, member checking, and adequate engagement with the data to assure the gathered data and the analyses conducted were rigorous and authentic. Merriam and Tisdell (2015) described triangulation as a practice of using multiple data sources to cross-check and compare data. Following this approach, this study collected both interview data and pictures drawn by the participants. Member checking involved meeting in person with the participants and asking for their thoughts about their transcribed interview. A few of the participants clarified some of the things they shared during the interview.

\section{RESULTS}

The following section describes the themes that were uncovered. The first main theme involved how participants expressed their social media use and expression of identify in Saudi Arabia. The second main theme involved how they expressed their social media use and expression of identify in the United States. Several subthemes under the main themes are described as well. We also included four representative samples of participants' drawings in this section.

\section{Social Media Use and Expression of Identity in Saudi Arabia}

\section{Unwillingness to Share Identity Online in Saudi Arabia}

When asked about the use of social media while in Saudi Arabia, all participants explained they had to be careful while using the Internet. They shared very little about themselves and never shared photos of their faces. The participants seemed to have developed extensive ways of protecting their online privacy. Suzan explained how she was completely unwilling to share parts of her identity online while in Saudi Arabia:

I was trying to not share anything personal or about my identity. Even my name was a nickname. I put a nickname for me and a picture that expressed my character or something, but I didn't share even with people I know sometimes.

Suzan took measures to protect her privacy and sometimes did not even feel comfortable sharing her identity online with people she knew. Expression of identity in Saudi Arabia was limited for most of the participants because of pressures from family and/or culture. Suzan demonstrated how she viewed social media in Saudi Arabia as compared to the United States in Figure 1. Her drawing shows that while in Saudi Arabia she found social media to be a dangerous place. She illustrated this danger with her drawing of a devil-like figure on the computer screen and a closed door that represents privacy. Her drawing of the computer in the United States, however, shows smiling friends and family. The United States led Suzan to feel social media was a place to connect with friends and family and find social interactions and not a place of danger. 


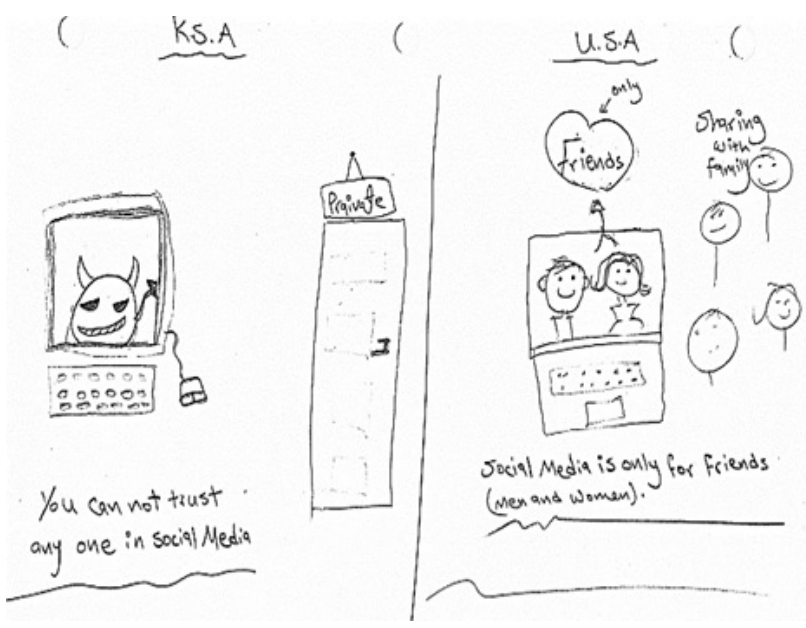

Figure 1: Suzan's Illustration of Social Media Use and the Expression of Identity

Maha described how cultural and familial expectations directed what she did and did not post on social media while in Saudi Arabia:

For a picture, I had a picture that is not of me, and even my name wasn't my real name, it was a nickname, I used a nickname. My parents, as a child, told me that it's dangerous to put my personal information on social media, so I never really put any part of my identity.

Because of her surroundings in Saudi Arabia, Maha was not willing to share any parts of her identity and was told sharing this information could put her in danger. She showed her profile picture in Saudi Arabia as a flower or something from nature, but she showed her profile picture as a photo of herself while in the United States.

Both Duaa and Faten used several privacy measures while in Saudi Arabia as well. Duaa said, "I wasn't willing to share any part of my identity. I didn't like to post my real name, I didn't like to post any kind of picture of me." Duaa was also unwilling to post information specific to her; instead, she relied on highly generalized information that could not be tied to her identity. When asked what kind of information she posted while in Saudi Arabia, Duaa said, "General information, maybe... No information about myself but more of information of like people would already know like, 'Oh, today is National Day." Duaa, like most of the other participants, was unwilling to express her identity online while in Saudi Arabia.

\section{Feeling Closed Off in Saudi Arabia}

Saudi Arabia seemed to present a more closed environment that impacted the women's identities and use of social media. The society of Saudi Arabia made the use of social media difficult for many females. As Dalal explained, "We are from 
kind of closed religious society so it was hard for me to share almost anything on social media while I was in Saudi Arabia." Dalal still felt cultural pressure when selecting profile pictures for social media, but her drawing indicated she had become more open on social media after coming to the United States. Although she is still cautious, she is able to be somewhat more open now that she is living in the United States.

Several factors about Saudi Arabia created challenges to using social media openly including the culture and family expectations. Explaining how she expressed her identity online while in Saudi Arabia, Maha said, "I did not really feel comfortable sharing my identity because my parents never really told me that I should post my identity on social media." The culture of Saudi Arabia largely dictated what was acceptable and unacceptable to post and share on social media.

Ahlam also expressed reservations about expressing her identity and thoughts online in Saudi Arabia. Explaining her concerns about having her identity public online, she said:

Yeah, I feel like threatened. If I have the people that I do know online, they know much about like my identity.... so that's why I don't post much. So how can I handle it? It's like I have to be very careful, very cautious about posting anything under my real name, like anything related to social manners, or something related to religion, or something related to open thoughts, or anything like that. I cannot do that. I have to be very careful.

As Saudi Arabia is a more closed society, which does not encourage open expression as much as in the United States, the participants remained careful and cautious about what kinds of thoughts and information they shared online. However, the United States seemed to provide a setting where Ahlam could open up on social media and feel more comfortable expressing her identity. This is visually represented

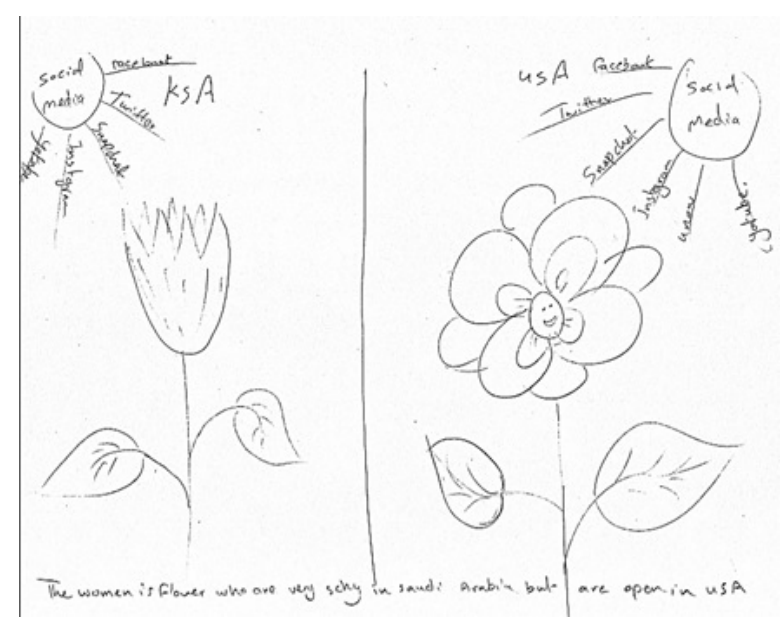

Figure 2: Ahlam's Illustration of Social Media Use and the Expression of Identity 
in her drawing (see Figure 2) where she is a closed flower in Saudi Arabia but able to bloom and open in the United States.

\section{Social Media Use and Expression of Identity After Coming to the United States}

\section{Becoming More Comfortable with Sharing Identity Online in the United States}

After coming to the United States, Duaa, Suzan, and Maha became more comfortable sharing parts of their identity on social media and did not use as many measures to protect their privacy. After coming to the United States, Duaa became more open about sharing some parts of her identity on social media but not others. She began using her real name but still did not feel comfortable posting photos of her face: "I don't post any kind of, I don't post my face in social media. I still don't like to put my picture on there but I do put my name."

Suzan explained how the environment of the United States impacted her views on expressing her identity on social media:

I think my identity, because the culture here is more open, compared with Saudi Arabia. There we have to hide more. As a woman I have to not show my name and a lot of things. But when I lived here like from the first month I felt okay with sharing just me and what my identity is so that people can interact with me as a person. Like, with my name, the fear of hiding my identity vanished from me, it didn't stay. This was the first thing that happened when I came here and I was even shocked for myself. I created a Facebook page for my account here in the US, and I put my real name. All my name, full name, even the family name, the whole thing.

Suzan was surprised by the sudden changes in her willingness to share information about herself on social media. While people in the United States might find it normal to share their full names, for Suzan, it was a big step in expressing herself online. Suzan also became more comfortable sharing photos of herself online but only with people she knew. She described her current Facebook profile picture and how it was mostly private: "It is not for the public, like just for friends. In Facebook, the profile could show the picture for anyone, but they cannot see the detail about me." Suzan described a privacy setting on Facebook that allows the public to see a person's profile picture as a small thumbnail but only allows an individual to enlarge it if they are accepted as a Facebook friend. This gave Suzan a level of privacy with which was comfortable, which ultimately allowed her to share her identity with the people she knows.

Maha also became more open to expressing her identity online after coming to the United States. She began to use her real first and last name and a picture of herself-although this picture was not a close-up. When she was asked about how her personal identity has developed since arriving in the United States, Maha described how her personal identity changed in relation to her social media use: "I feel comfortable using my personal identity, my first and last name in social media in the US compared to back home in Saudi Arabia." Instead of using a nickname, Maha became comfortable sharing her real name on social media. 
In addition to sharing her real name on social media, Maha also began using a picture of herself as her profile picture. However, she still takes certain measures to protect her privacy and personal image. Maha explained her role in selecting her current profile picture:

I have two social media. I have a personal account on Instagram and a personal account on Facebook, and in those profile pictures, I have a profile picture of myself, but you can't really see me in the profile picture... It's a picture of me, but it's far away in the distance, and I have sunglasses, so you can't really see my face. It's a full-body picture so you can't identify who it is unless you really know me.

By using a picture of herself far in the distance and wearing sunglasses, Maha navigated a balance between sharing her identity and maintaining her privacy. This allowed her to share her identity with friends and family but remain somewhat anonymous to those who did not personally know her. Maha also shared how she was influenced by the way Americans use social media. When she was asked if her use of social media while in the United States has affected her personal identity, she explained:

Yes, I think my use of social media in the US has affected my personal identity because anyone could freely use their identity here in the US, while in Saudi Arabia a lot of people do not really use personal identity such as profile pictures, names, etc., but here in the US it's very normal to use your profile picture and to put your real name, so I guess, the people around me really affected me.

The use of social media is quite different in Saudi Arabia as compared to the United States. For example, the Saudi government both censors and monitors social media (Freedom House, n.d.). While the United States views social media as a tool to express one's personal identity, Saudi Arabia finds the use of social media as potentially dangerous and threatening to one's identity. As a result, Saudis protect their privacy online and keep profiles unidentifiable. Maha demonstrated how the U.S. environment could influence the way Saudi female students begin using social media to express personal identity.

\section{Becoming More Open in the United States}

After spending time in the cultural setting of the United States, many of the participants became more open and expressive both in their personal lives and on social media. Elham felt she became less shy and more confident after coming to the United States: "I became less shy when I do formal presentations but in social events I'm still shy but not to the same extent." She also described one factor of the U.S. educational environment that greatly impacted her identity: "Being educated in a mix environment and supervised by male professors who view Muslim women as brave, smart, and caring social beings." 
For some participants, the use of social media and online interactions changed quite dramatically after coming to the United States. Rahaf explained how her use of social media changed after coming to the United States:

Actually when I came to United States, I have more freedom, but not a lot more. It's a little bit. In social media, still, they can see me in Saudi Arabia using social media. It's improving a lot. I became more loose, more relaxed, more comfortable using social media while I'm in United States, but in Saudi Arabia, I have to follow my culture's rules, so I can't use it very openly.

Rahaf's feelings about her use of social media in the United States as compared to Saudi Arabia seemed to be reflected in her drawing (see Figure 3). Her drawings of closed and open books symbolize her increased openness after coming to the United States from Saudi Arabia. Similarly, Haya drew how her mind became more open after coming to the United States (see Figure 4). In Saudi Arabia, her mind was represented by one flower under a crescent moon, which seemed to represent Saudi Arabia. In the United States, however, her mind grew and it is symbolized by more flowers and foliage. The United States was also drawn as a shining sun that allowed her mind to grow.

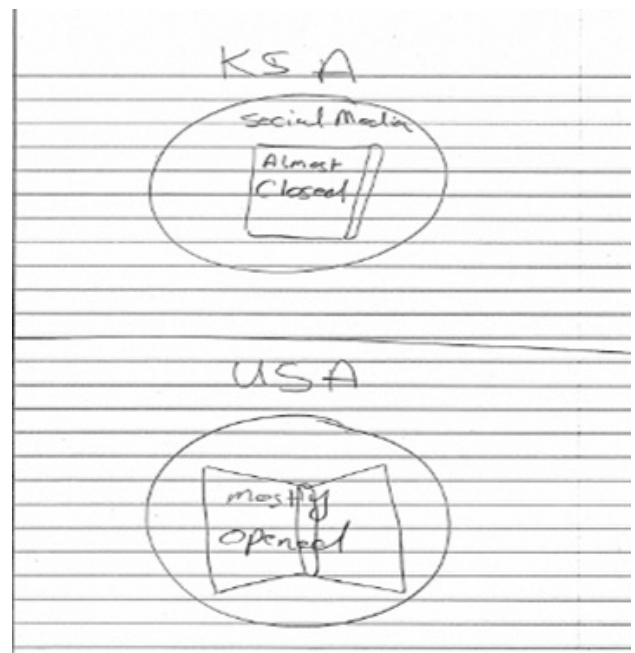

\section{Figure 3: Rahaf's Illustration of Social Media Use and the Expression of Identity}

\section{Becoming More Independent in the United States}

In addition to becoming more open in the United States, most of the participants also indicated they became more independent. While few females explicitly said they became more independent, several of them described new behaviors and outlooks that demonstrated their increased sense of independence in the United States. When asked 
how her personal identity had developed since arriving in the United States, Renad clearly expressed she became more independent by stating, "I have become more independent, more aware of the world and I became a mother so I became more protective and care about the future of my children." Huda also identified an increased sense of independence when she explained how her personal identity changed since arriving in the United States:

I feel like I started to look out for myself more and be more independent. Living in United States gave me a chance to explore myself deeper, and have a better control on my emotions and thoughts or in other words, I learned how to deal with the emotions that result from life stress.

Huda indicated she became more independent and this identity change was a positive one. Her increased independence helped her mature emotionally and deal with stress in a better way.
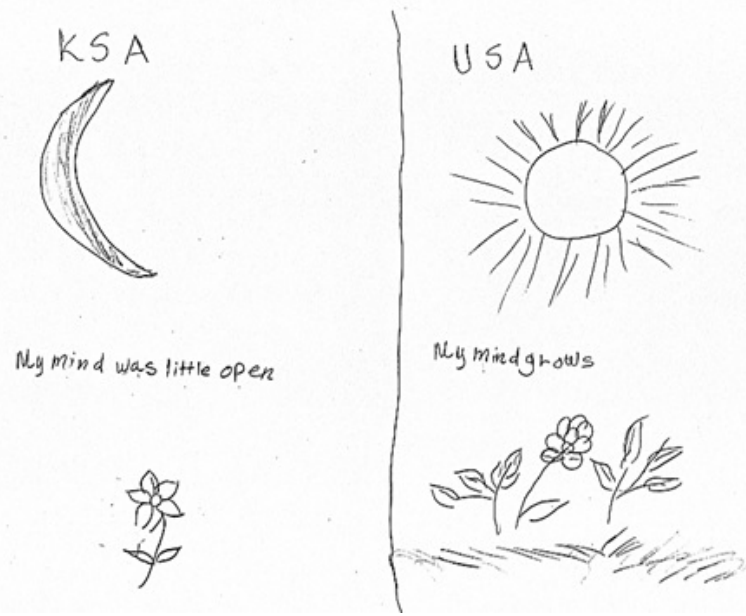

\section{Figure 4: Haya's Illustration of Social Media Use and the Expression of Identity}

In addition, Elham described a variety of behaviors that began after she came to the United States. While she did not directly state she became more independent, Elham described several behaviors that demonstrated her increased independence:

I was open to try new things to me in the new culture. For example, swimming in an Islamic bathing suit and playing in a water park with my friends, walking for stress relief with my friend and going to the gym, staying late in Starbucks with my laptop, articles, and my friends, driving a car and speeding in the highway, and finally, having a sleepover with my female friends, which I used to not have when I was back home. In sum, I became an outgoing and outdoor person and I didn't want to miss anything. 
Elham described many behaviors commonplace to an American but were new and different for her. She indicates the cultural setting of the United States allowed her to explore new ways of living that called for an increased sense of independence.

Americans might be confused by the changes these participants described as they have lived in a culture that expects independence and sees independent behaviors as normal and common. However, independence was a new concept for the participants in this study as the culture from which they originated often expected them to be dependent. In Saudi Arabia, females must travel with a male guardian, which is typically a father, brother, or husband. For example, Elham might not have been able to stay late in a coffee shop because she would be dependent on her male guardian. Thus, the cultural setting of Saudi Arabia impacted the identity of the females and led them to be more dependent. In other words, living in the United States' culture that expects, and often requires, a certain level of independence effectively changed the participants' respective identities and shaped their sense of independence.

\section{Protecting Online Privacy in the United States}

Although many participants increased their openness on social media to some degree after arriving in the United States, most still had concerns about privacy and the need to protect their identities online. Samah stated, "I know myself, if there is any concern, I don't post things. I usually post natural things, or somewhere, or places I've visited, or something I did." Although Samah does not explicitly say it, it is implied she knows she cannot go beyond neutral posts such as nature scenes or places she has visited. Similar to Samah, Waad was also selective about what kinds of information and pictures she posted because the culture of the online community she was a part of expected her to post certain things but not others.

Rahaf explained she still has difficulties posting a picture of her face online and how she manages this concern:

I have a difficult time posting my face. Like if it's myself taking pictures of myself. But if it's my body from the back or if it's me walking while hiding my face and identity, I can post it; it's okay. I'm not that strict about posting my whole body because my body is not... They don't know who I am, so I can post my children's faces or my whole body.

In answering a question about her privacy concerns online, Rahaf also reiterated her concerns about posting opinions under her real name or in association with any identifiable information. "If it's against my family, culture, I will not post anything leading to me, like my children or anything else," she explained.

Fahdah utilized the tools and settings made available by social media platforms to protect her identity and privacy online. She made all her social media accounts private and felt more comfortable sharing personal information on platforms that afforded greater privacy such as Instagram: "I don't have my social media stuff in public, everything is set to private. The only thing public is Twitter, and I don't post anything about my personal life." She also explained why Instagram was particularly useful to her in protecting her privacy: 
Something in social media...it's called Instagram. All these years, I was using just my nickname, but just last month I changed my Instagram to my real name, and I made my status I'm married, and I'm PhD student, so I have been changing in this way. I think it's a good change.

\section{DISCUSSION}

Many participants indicated they experienced some changes to their identities after coming to the United States. For example, Saudi Arabia was seen as a more closed environment that created more closed identities. The United States was described as a more open environment for the participants and gave them greater independence. Changes to their identity were often linked to changes in how they viewed and used social media. Many of the participants became more comfortable with social media and less fearful about privacy concerns. They felt they could express their identities on social media to a greater degree and enjoyed using it to connect with others. While most of the participants still did not post pictures of themselves on social media, they were more open to it and shared some pieces of their identities online. However, cultural influences from Saudi Arabia still impacted their feelings toward social media. Many of the participants were careful about what they shared online and tried to find a balance between open expression and the protection of their privacy.

The findings of this study not only reflected previous research (Y. Kim, 2011a, 2011b; Lefdahl-Davis \& Perrone-McGovern, 2015), but also identified some new insights. Y. Kim (2011a, 2011b) explained that students who study in a Western culture often experience changes in their beliefs and behaviors. They find their identities had shifted and became more open as they interacted with a different culture. Lefdahl-Davis and Perrone-McGovern (2015) studied identity changes for Saudi female students and found that they reported becoming more open and independent after living in the United States for a period of time. In the current study, the participants experienced shifts in their identities toward greater openness and independence. However, they still maintained their foundational identities that were rooted in their cultural backgrounds. This caused them to continually negotiate the tension between their shifted identities and their foundational identities.

The findings of this study indicate Saudi females studying in the United States found ways to make social media sites more suitable to their personal and cultural needs. Often, the participants would set their Facebook profiles to private so only those they added as "friends" could see their information. This helped them protect their identity while still using social media to connect with others. Kimmons (2014) explained some social media sites developed in the United States such as Facebook asks users to provide their relationship status and sexual orientation, which might be considered as private information to those of a different culture. While Kimmons did not specifically discuss the use of Facebook and other social media sites by Saudi females, his claims about conflicting cultural systems were relevant to the findings of the current study.

This finding may also be explained by E. Kim (2012), as all the Saudi females who were interviewed in the current study had been in the United States for at least 2 years, some as many as 9 . These participants may have already reached the integration 
stage where behaviors from their culture of origin were integrated into and inseparable their daily actions. Even so, the participants in the current study were still careful not to add Saudi males because they worried Saudi males would be more apt to judge their use of social media and might misinterpret the acceptance of a friend request. Furthermore, Guta and Karolak (2015) found a strict separation of males and females with males asserting much control over females in Saudi Arabia. The findings of this study expanded on E. Kim's (2012) findings by further explaining Saudi women's cultural considerations when using Facebook.

Although the participants in this study became more open toward the use of social media to express their identities, many of them still concealed parts of their identities online. Most of the participants used nicknames on Facebook while in Saudi Arabia but once they arrived in the United States, they felt comfortable using their real names online. Guta and Karolak (2015) found one of the main identityconcealing behaviors for Saudi females was the use of nicknames. However, Guta and Karolak's study was only conducted in Saudi Arabia and did not look at changes in social media usage for Saudi females living outside Saudi Arabia. The findings of the present study suggest the cultural setting influenced the use of nicknames or real names by Saudi females. Although the U.S. setting might lead Saudi females to become comfortable using their real names, the participants still largely felt uncomfortable posting pictures of themselves on social media. Guta and Karolak explained this discomfort was one of the main identity concealment behaviors for Saudi females in Saudi Arabia. It seemed this behavior continued for the Saudi participants in this study even after they arrived in the United States.

In terms of limitations of the study, two limitations to this study need to be addressed. First, we conducted the interviews in English and not in the participants' native language. This probably limited free and expanded explanations of their perspectives and thoughts that Arabic might have allowed. Second, although the participants were from Saudi Arabia, we did not ensure they were representative of the various subcultures within Saudi Arabia, which may have different degrees of religious and cultural perspectives. For future research, other researchers could question if reported changes in behavior, beliefs, and attitudes, such as greater openness and increased independence, were characteristic of just female students from Saudi Arabia, whether these changes also occurred for male students from Saudi Arabia, or whether it was more widespread throughout Muslim communities in the world. Another future research avenue could follow Saudi women once they return to Saudi Arabia to see if they revert to more closed self-identities in their social media use.

\section{REFERENCES}

Ahlquist, J. (2015). Developing digital student leaders: A mixed methods study of student leadership, identity, and decision making on social media [Master's thesis, California Lutheran University]. http://pqdtopen.proquest.com/doc/1705809805.html?FMT=AI

Al-Saggaf, Y. (2011). Saudi females on Facebook: An ethnographic study. International Journal of Emerging Technologies and Society, 9(1), 1-19. 
Aljasir, S., Woodcock, A., \& Harrison, S. (2014). Usage of social network sites amongst Saudis: Why do Saudi university students have multiple Facebook accounts? International Journal of Social Science and Humanity, 4(4), 293-297.

Buckingham, D. (Ed.). (2008). Youth, identity, and digital media. MIT Press.

Creswell, J. W. (2012). Qualitative inquiry and research design: Choosing among the five traditions (3rd ed.). Sage.

Dalton, J. C., \& Crosby, P. C. (2013). Digital identity: How social media are influencing student learning and development in college. Journal of College and Character, 14(1), 1-4.

Earley, P. C. (1993). Culture, self-identity, and work. Oxford University Press.

Freedom House. (n.d.). Freedom in the world 2020: Saudi Arabia. https://freedomhouse.org/country/saudi-arabia/freedom-world/2020

Giddens, A. (1991). Modernity and self-identity: Self and society in the late modern age. Stanford University Press.

Guta, H., \& Karolak, M. (2015). Veiling and blogging: Social media as sites of identity negotiation and expression among Saudi women. Journal of International Women's Studies, 16(2), 115-127.

InterNations. (2018, October 12). Living in Saudi Arabia. Retrieved from June 11, 2019 from https://www.internations.org/saudi-arabia-expats/guide/living-insaudi-arabia-15364

Kaplan, A. M., \& Haenlein, M. (2010). Users of the world, unite! The challenges and opportunities of Social Media. Business Horizons, 53(1), 59-68.

Kim, E. (2012). An alternative theoretical model: Examining psychosocial identity development of international students in the United States. College Student Journal, 46(1), 99-113.

Kim, J. Y. (2018). A study of social media users' perceptional typologies and relationships to self-identity and personality. Internet Research, 28(3), 767-784.

Kim, Y. (2011a). Diasporic nationalism and the media: Asian women on the move. International Journal of Cultural Studies, 14, 133-151.

Kim, Y. (2011b). Female cosmopolitanism? Media talk and identity of transnational Asian women. Communication Theory, 21, 279-298.

Kimmons, R. (2014). Social networking sites, literacy, and the authentic identity problem. TechTrends, 58(2), 93-98.

Kutbi, A. I. (2015). How undergraduate female students in the Kingdom of Saudi Arabia perceive social media as a learning tool: An exploratory study [Master's thesis, University of Windsor]. Scholarship at UWindsor. http://scholar.uwindsor.ca/cgi/viewcontent.cgi?article=6289\&context=etd

Lefdahl-Davis, E. M., \& Perrone-McGovern, K. M. (2015). The cultural adjustment of Saudi women international students: A qualitative examination. Journal of Cross-Cultural Psychology, 46(3), 406-434.

Menea, E. (2013). Women in Saudi Arabia are caught in a system of gender apartheid. http:/www.dw.com/en/women-in-saudi-arabia-are-caught-in-asystem-of-gender-apartheid/a-17330976

Merriam, S. B., \& Tisdell, E. J. (2015). Qualitative research: A guide to design and implementation. John Wiley \& Sons. 
Papacharissi, Z. (2010). A networked self: Identity, community, and culture on social network sites. Routledge.

Papacharissi, Z. (2013). A networked self: Identity performance and sociability on social network sites. In L. F. Francis, L. Leung, J. L. Qiu, \& D. S. Chu (Eds.). Frontiers in new media research (pp. 207-221). Routledge.

Pattaro, C. (2015). New media \& youth identity. Issues and research pathways. Italian Journal of Sociology of Education, 7(1), 297-327.

Sofi, L. A. (2015). Teaching English in Saudi Arabia through the use of multimedia [Master's thesis, University of San Francisco]. USF scholarship. http://repository.usfca.edu/cgi/viewcontent.cgi?article=1143\& context=capstone

Stone, G. (1981). Appearance and the self: A slightly revised version. In G. Stone \& H. A. Farberman (Eds.), Social psychology through symbolic interaction (2nd ed., pp. 187-202). Wiley.

Tess, P. A. (2013). The role of social media in higher education classes (real and virtual)-A literature review. Computers in Human Behavior, 29(5), A60-A68.

$\mathrm{Xu}, \mathrm{Q}$., \& Mocarski, R. (2014). A cross-cultural comparison of domestic American and international Chinese students' social media usage. Journal of International Students, 4(4), 374-388.

TAHANI ALRUWAILI, PhD, researches social media studies, distance education, and cross-cultural studies. Email: tahani.tr@gmail.com

HENG-YU KU, PhD, is a professor in the College of Education and Behavioral Sciences at the University of Northern Colorado. His major research interests lie in the area of technology integration, online learning and teaching strategies, and online collaboration. Email: heng-yu.ku@unco.edu 